\title{
ON PAREMIOLOGICAL GRADUONYMY IN THE UZBEK LANGUAGE
}

Abdullaeva Nargiza Erkinovna,

Scientific researcher and teacher of English Philology Department, National University of Uzbekistan named after Mirzo Ulughbek, Republic of Uzbekistan Phone number: +998998005525, E-mail: 6052789@mail.ru

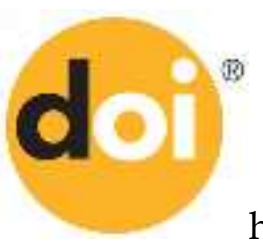

http:/ / dx.doi.org/10.26739/2573-5616-2018-1-2-5

Abstract. In contemporary scientific life of language theory, among linguistic paradigms such as synonymy, antonymy, homonymy, polysemy, meronymy (partonymy), holonymy, hyponymy a new linguistic phenomenon "graduonymy" appeared. Uzbek linguists Begmatov et al. (1989), Bozorov (1995), Arifjonova (1996), Djumabaeva (2014, 2016a,b) investigated this issue firstly and then it has been studied in other languages (Vokhidova (2008) in German; Djumabaeva (2014, 2016a,b) in English). This phenomenon identifies mainly lexical-semantic relations of words and phrases. Therefore, its essential value is in the field of semantics. This paper shows the types and main peculiarities of graduonymic relations of Uzbek proverbs by illustrating the framework with the translations and equivalents of these proverbs in English (not all Uzbek proverbs have English equivalents) for identifying their meanings as well. Scientists consider proverbs as complex linguistic and folklore units at the same time, and analyse them in various ways. Here, I aim to investigate two types of graduonymic relations of proverbs: 1) among the effectiveness and strength of their whole meanings and 2) among their 
components. The results and recommendations of this article provide defining paremiological graduonomy from the semantic point of view.

Keywords: semantics, graduonymy, graduonymic relation, graduonym, graduonymic row, paremiology, micrograduonymy, macrograduonymy, quantitave graduonymy, cyclic graduonymy, unique graduonymy. 
Language without meaning is meaningless.

Roman Jacobson

\section{Introduction}

As a complex system, a language includes various linguistic units (phonological, morphological, syntactical, stylistic, lexical, phraseological, etc.) and interrelations among these units in its content. By the time, it has been proved that a natural language is not an abstract system and it cannot be placed in a constant frame because of its permanent changeability. According to the history of linguistics, a language was analysed as one of the means of human communication that follows some certain rules and has obvious unchangeable features that can be contained in one chart. Nevertheless, then it was identified that any language in the world has its complicated peculiarities; there are always some exceptions in its rules. Especially, it was proved that a language is an object with many various units, and their relations and functions, which are remodelling permanently. The main reasons of this process are its ontological and epistemological features. In other words, a human expresses his ideas that are based on the reflection of things and events, which exist in the world, in his mind with the help of his knowledge and worldview by his language. The world is itself complex and changing day by day. Therefore, both human mind that reflects all beings and a language that delivers people's ideas to each other are not simple and fixed structures, but they are complex variables. Moreover, the systematic study of the structure and development of a language - linguistics has also been developing, creating its new theories, rules, disciplines, phenomena and terms for many centuries.

Modern linguistics is waiting solutions of its new issues. These issues cannot be disclosed easily only by creating a new linguistic notion or term and defining its meaning(s) and function(s), but scientists have to implement wide scientific, methodological, philosophical investigations, and, of course, practical experiments to find solutions of linguistic issues as well. It has to be mentioned that successful linguistic investigations have been progressed and are still fulfilling in the world science nowadays. Although those many scientific researches are results of different centuries, they relate to each other directly or indirectly and those all factors help to develop general and applied linguistics more and more.

As we know from the history of linguistics, most of early linguistic investigations were devoted to the study of grammatical features of a language. But then, from the beginning of the XIX century (1814) to the second Social science and humanities

Generalization of scientific results 
quarter of the $\mathrm{XX}$ century was the time of comparative-historical and comparative-typological approaches of linguistics as Franz Bopp, Rasmus Rask, Jacob Grimm, Christopher Vostokov, August Schleicher, Hermann Osthoff, Alexander Potebnya, Ferdinand de Saussure, Boduen de Courtenay and other linguists worked on the analyses of both similarities and differences of human languages. As a result, language families and their subtypes were classified according to the degrees of their genetic and historical relationships. However, still there are several natural languages in the world, which have not been studied from the genetic point of view.

The culmination of the general linguistics progress is seen at the time of Swiss linguist Ferdinand de Saussure's "Course in General Linguistics" (Saussure, 1916). He defines a new science of "semiology" that studies the life of signs within society and he considers that this science is the part of social psychology; as a language is the system of signs, linguistics is the part of semiology (Saussure, 1916). Besides, he distinguishes language from speech, signified from signifier, syntagmatic relations and paradigmatic relations, synchronic axes from diachronic axes, etc. His works provide flourishing of general and structural linguistics, and become the foundation of new fields of linguistics as semiotics (including pragmatics, syntactics and semantics), sociolinguistics, cognitive linguistics, linguo-cultural study, paralinguistics, psycholinguistics, ethnolinguistics, computer linguistics, corpus linguistics and others.

Because of its wide relevance, semiotics is not only the field of linguistics, but also the part of other human sciences. Grzybek conveys semiotics as a branch of science which studies signs, or systems, and the processes of sign generation (semiosis) and usage, has rather been a methodological tool used by individual sciences, interested in a methodological generalization of their results (Grzybek, 2014). Morris outlines three semiotic dimensions in his semiotic studies: 1) the pragmatical dimension, 2) the syntactical dimension, 3) the semantical dimension (Morris, 1938). According to Morris's definitions to these three disciplines, pragmatics is concerned with the relation between sign and sign users; syntactics is directed towards the formal relations of signs to one another; and semantics concentrates on the relations of signs to the objects to which the signs are applicable (Morris, 1938). This paper concentrates reader's attention to the field of semantics of proverbial study.

The area of semantics is very large and it is connected with all other branches of linguistics directly, because it deals with meaning as Allan notes: "Semantics is the study of meaning in human languages" (Allan, 2006). Every 
notion or object possesses meaning, besides we cannot utter our ideas without meaning. As Allan assumes: "The expression of meaning through language is an essential means of cementing human bonding and of displaying it to others, both at the individual and the community level" (Allan, 2006). If there is not any meaning in our sentences, our intention is indefinite and not understandable for listeners or readers. Taking peculiarities of linguistic units into account, semantics is also divided into some specific subdivisions. Grzybek classifies semantics into four types:
a) lexical semantics;
b) sentence semantics;
c) text semantics;
d) discourse semantics (Grzybek, 2014).

Each type has its own wide outline of research in any natural language. Moreover, all of them have interrelations among them; in other words, they cannot exist without each other. This paper aims to work in the fields of mainly lexical semantics and partly sentence semantics.

The structure of this paper is as follows. In Section 2, I shall examine one of the new phenomenon of modern linguistics - "graduonymy" from the lexical semantic point of view, differentiate graduonymy from other linguistic notions and paradigms, and define its types and some peculiarities as well. Section 3 is devoted to the study of proverbs, looking back to the history of paremiology and analysing some essential works on this issue as a researcher who is inspired from those works to learn paremiology. I shall use holistic analysis on the investigation of paremiological graduonymy in Section 4 . Section 5 concerns the componential analysis of paremiological graduonymy; besides, its subsections defines types of graduonymy that are frequently faced in Uzbek proverbs. I shall illustrate definitions and hypotheses with examples, as well as demonstrating Uzbek proverbs with their word-for word translations (ww) in English and English equivalents (ee) if they have. In Section 6, I shall conclude my paper.

\section{Graduonymy as a lexical semantic paradigm}

In the semantic subfield of lexical semantics in Uzbek linguistics one of the new notions of modern linguistics - "graduonymy" has appeared in the row of lexical-semantic relations among linguistic units such as synonymy, antonymy, homonymy, polysemy, hyponymy, meronymy (partonymy), holonymy, etc. The main stimulus of investigating graduonymy is stepping of linguistics from the empirical (descriptive, explanatory) stage to the dialectical (having relations, essence) stage. In other words, linguistic units are learned Social science and humanities

Generalization of scientific results 
not only separately from each other, but also taking their relations among them and their influences to one another into consideration in analysing and identifying them from the linguistic point of view. This methodological process and above mentioned factors are reflecting in both general and applied linguistics now. Particularly, in Uzbek linguistics the paradigm of graduonymy has come into existence based on the logical laws of negation for negation, the unity and fight of contrasts, changing of quantitative variables into qualitative variables, and the law of dialectical logic that means the third is conditional.

Graduonymy is defined to be a paradigmatic relation of opposition among linguistic units according to increasing or decreasing of their particular sign (Djumabaeva, 2014).

The notion of graduonymy has its history that began in Trubetskoy's (1960) and Jacobson's (1962) scientific works, which are dedicated to phonology. They analysed gradual oppositions of phonemes taking the degree of their signs into consideration in the phonological system of a language. The Uzbek linguist Giyasov uses the term "leksik gradual oppozitsiyalar" (lexical gradual oppositions) that reflects gradual oppositions in the semantic features of lexemes in the Uzbek language (tuzuk - durust - yaxshi - ajoyib; chiroyli ko'rkam - suluv - go'zal - zebo) (Giyasov, 1986).

The term "graduonymy" was firstly used in 1989 in the Uzbek linguistics as one type of the semantic relations of words and it was marked as lexical graduonymy. Based on the types of semantic relations that are implemented among words, words are divided into lexical-semantic groups (LSG). Moreover, the term "graduonymy" is formed artificially by adding the suffix "onymy" as in the other terms of lexical-semantic paradigms such as "synonymy", "antonymy", "hyponymy" to the Latin word "gradus" ("degree", "level") (Begmatov et al., 1989).

Graduonymic relations exist not only among lexical units, but also among other linguistic layers and their units in any language, so it is a universal notion of a general linguistics. Several scientists have proved this hypothesis; especially, in the Uzbek linguistics (Bozorov, 1995; Djumabaeva, 2014, 2016a,b) its investigation has wide encompassment. This paper concerns only about lexical graduonymy.

The row or scale that contains graduonyms is called graduonymic row or graduonymic scale (Djumabaeva 2016a). Djumabaeva emphasises that there are synonymic relations among the units situated on the right or left side of a graduonymic row's dominant and sometimes antonymic relations among 
graduonyms placed on the opposite sides of a graduonymic row, eg.: tiny small - medium - big - enormous - gigantic (Djumabaeva 2016b). Here tiny and small, and big, enormous and gigantic are synonyms; medium is dominant, tiny and gigantic, tiny and enormous, small and big are antonyms. There are also some graduonymic row in which we cannot find antonymic relations, eg.: egg chicken - hen/cock; lake - tributary - river - sea - ocean. As Djumabaeva mentions a graduonymic row has to contain not less than three graduonyms; graduonymic rows that contain synonymic and antonymic relations are called "macrograduonymic rows", graduonymic rows that have only synonyms are called "micrograduonymic rows" (Djumabaeva 2016a). Nevertheless, one should clarify that graduonymy and synonymy are not same paradigms: synonymy is based on the sameness of meanings; graduonymic relations are built on the opposition of meanings.

It should be noted, there are some linguistic phenomena that can be confused as having similarity to the notion of graduonymy. For example, according to its sense climax (gradation) looks like graduonymy:

"Climax is an arrangement of sentences (or of homogeneous parts of one sentence) which secures a gradual increase in significance, importance, or emotional tension in the utterance, as in: It was a lovely city, a beautiful city, a veritable gem of city." (Galperin, 1971). Galperin clarifies three types of climax: logical climax, emotional climax, quantitative climax; and all of them are kinds of stylistic means, because all of them are seen in a text. Differs from climax graduonymy does not define the relation of words or sentences in a text; it is a pure linguistic paradigm which exists without a text or discourse. Moreover, the issues of intensification, hyperbole and gradation also possess some features that resemble graduonymy, but all of them are seen in a text or discourse. Therefore, they are learned as the notions of speech, but only graduonymy is the phenomenon of a language.

Bierwisch uses the term of "gradation" for degrees of adjectives in his book "The Semantics of Gradation". In his work he conveys comparative, equative, superlative degrees of adjectives and some adverbs in the German and English languages with their semantic and syntactical features as in the following examples:

Fritz ist kleiner als Hans.

Fritz is shorter than Hans (Bierwisch, 1989).

Kennedy and McNally investigate semantics of gradable predicates that can be used with degree modifiers (eg.: well, much, very) in a context and some scale structures dealing contextual usage of adjectives and adverbs (Kennedy 
and McNally, 2005). Still, one cannot think that those theories link with the paradigm of graduonymy as it is a pure lexical notion.

Russian linguists Yespersen (1958), Katsnelson (1965) and Stepanov (1975) gives some ideas and examples, which are about the issue of graduonymy (eg.: истощённый - тощии - худой - сухопарыи - нормальныи упитанный- полный).

In English linguistics, Cruse conveys some linguistic states that contain hierarchical arrangement in his prominent theoretical book "Lexical Semantics". Cruse demonstrates the non-branching hierarchy of levels constituting a sentence as follows:

sentence level

clause level

phrase level

word level

morpheme level (Cruse, 1986)

Besides, Cruse distinguishes several types of lexical units according to their semantic hierarchic relations and sequences based on degrees of a scaled property, which have resemblance with some types of graduonyms (they will be seen in Section 5):

- lexical chains (have pure linear ordering): shoulder - upper arm - elbow - forearm - wrist - hand; birth - childhood - adolescence - adulthood - old age - death; beginning - middle - end; ocean - sea - lake - pond - puddle;

- lexical helices (have hybrid linear/cyclical ordering): Sunday - Monday - Tuesday - Wednesday - Thursday - Friday - Saturday; spring - summerautumn - winter; morning - afternoon - evening - night;

- lexical circles (lack of top and bottom lexical units, there is no unique item related in the relevant way to all the other items in the set): red purple - blue - green - yellow - orange - red - purple - ... (the order of these lexemes is repeated again and again in a circle direction);

- rank-terms (have discontinuous scale; in other words, lexical units vary in discrete jumps): general - colonel - major - captain - lieutenant ....; first - second - third - fourth - sixth - ...; half - third - quarter - fifth - sixth - ...; twins - triplets - quadruplets - quintuplets - sextuplets - ...;

- degree-terms (non-gradable continuous (vary continuously) scale): mound - hillock - hill - mountain; fail - pass - credit - distinction; baby child - adolescent - adult; egg - caterpillar - chrysalis - butterfly;

- grade-terms (gradable continuous (vary continuously) scale): freezing -cold-cool-warm-hot-scorching; atrocious - bad-indifferent-average 
- fair - good - excellent; minuscule - tiny - small - big - huge - gigantic (Cruse, 1986; Cruse, 2002).

All these lexical groups reflect features of lexical graduonymy as follows:

(1) there are neither intensifying words, nor affixes to form gradual order of lexical units;

(2) hierarchic relations of words are constructed based on not their contextual meanings, but their lexical meanings;

(3) the members of these rows differ from each other by their degree of quality and quantity;

(4) the members of each row are gathered around one seme.

Several Uzbek linguists have investigated on the issue of graduonymy: its features, its similarity and difference from other linguistic notions. Besides, as it was mentioned above, it was proved that graduonymy is a universal linguistic phenomenon that can be felt in any linguistic layer (phonological, morphological, syntactical, stylistic, lexical, phraseological, etc.) of a language.

From the philosophical point of view, graduonymy exists in the world in incredible number and variety; so a human mind is too weak to reflect all of them in it, otherwise the number of lexemes and linguistic units become very many that human mind cannot remember them at all. According to the dialectical and ontological bases of graduonymy, it is found in a language mainly in a lexical type of it.

Uzbek linguist Bozorov explains the dialectics of form and meaning of linguistic units as in the following graph, and classifies nine groups of lexical units by clarifying lexical-semantic relations of them as follows:

“Meaning (sense) $(\mathrm{M})$ : sameness $(\mathrm{S}) \rightarrow$ differentiation $(\mathrm{D}) \rightarrow$ opposition $(\mathrm{O})$

Form (sound form) $($ F): sameness $(S) \rightarrow$ differentiation $(D) \rightarrow$ opposition $(\mathrm{O})$

1) FS - MS: repeated words

2) FS - MD: polysemy

3) FS - MO: enantiosemy (auto-antonymy), homonymy

4) FD - MS: doublets

5) FD - MD: paronymy

6) FD - MO: antonymy

7) FO - MS: subtypes of doublets

8) FO - MD: subtypes of synonyms

9) FO - MO: subtypes of antonyms" (Bozorov, 1995. The author's translation from Uzbek into English).

Taking into consideration that graduonymy is also a type of lexicalsemantic relations, it has a place in above-mentioned combination as well. As 
graduonyms do not repeat each other in form, have frequently synonymic and sometimes antonymic relations, graduonymy may reflect this complex combination:

$\mathrm{FO}^{1}-\mathrm{MD}^{1} \rightarrow \mathrm{FO}^{\mathrm{n}}-\mathrm{MD}^{\mathrm{n}} \rightarrow \mathrm{FO}^{\mathrm{m}}-\mathrm{MO}^{\mathrm{m}}$ : graduonymy

Opposition in form and differentiation in meaning is the constant feature of graduonymy (ocean - sea - lake - pond - puddle), opposition in both form and meaning is characteristic to some graduonymic rows (freezing - cold - cool warm - hot - scorching). Relations of lexical meanings of words, which are enlivened in a human brain separated from context, lie in the process of lexical graduonymy. A graduonymic row contains words that name things, events, and sign-quality having semantic similarity and same social value, but varying in quantitative factors. Arifjonova notes graduonyms are gathered around one leading word, which is called "dominant" (as in wide - normal narrow, big - medium - small); sometimes dominants do not occur in graduonymic rows and they can substitute all members of those graduonymic rows. She gives the following example in Uzbek: the lexeme of "ayol" (woman) is a dominant in the graduonymic row of qiz (girl) - juvon (young married woman) - xotin (middle-aged married woman) - kampir (old woman) (Arifjonova, 1996). Here, the word "ayol" (woman) can express all members of this graduonymic row. Additionally, Arifjonova emphasises the following peculiarities of lexical graduonymy:

- any member of a graduonymic row remembers the meanings of other members;

- only one of the members of a graduonymic row can be chosen and used in a particular context;

- graduonyms of a lexical graduonymic row are similar in meaning, but every member differs from the others with its private feature;

- graduonyms of one row can take the same position in speech:

Darcha (A hatch) / Eshik (A door) / Darvoza (A gate) qurildi (was built). (Arifjonova, 1996. The author's translation from Uzbek into English).

Paying attention to these features of lexical graduonymy one can feel that this phenomenon defines paradigmatic relation of lexical units as they have concrete lexical-semantic senses in a language.

\section{Paremiology}

The proverb is a complex unit of a language reflecting human life experiences and practice, his attitude towards society, history, culture, mentality, ethic and esthetical senses, positive and negative characters. It is "a traditional figurative saying which can form a complete utterance on its own" Social science and humanities

Generalization of scientific results 
(Norrick, 2014). During many centuries, proverbs are formed and polished to constitute compact and short poetic forms. They possess the peculiarities of dialectical unity of form and meaning; besides, often rhyme and figurative stylistic devices (mainly metaphor), sometimes polysemy is characteristic to them. Every nation gathers huge culture and experience of life during many ages, and hand down it as national heritage to their generation. Proverbs are also parts of national heritage.

The study of proverbs, sayings and aphorisms is called "paremiology", which is taken from the Greek word paroimia (proverb, maxim, saw) (https://en.wikipedia.org/wiki/Paremiology\#cite_note-1). Paremiography studies collecting them and creating proverbial dictionaries respectively. A number of paremiologists have examined various aspects of proverbs; I intend to mention some of them being essential to be connected with the current work briefly.

Although proverbs are short in form, they express broad sense of human life. The origin of proverbs is controversial issue that whether they are created by an individual or by the nation which they belong to. Mieder assumes that they are not created by the folk but rather by an individual and identifies four major sources of common European proverbs (Mieder, 2014). He cites about formation of proverbs:

"Proverbs, like riddles, jokes, or fairy tales do not fall out of the sky and neither are they products of a mythical soul of the folk. Instead they are always coined by an individual whether intentionally or unintentionally. If the statement contains an element of truth or wisdom, and if it exhibits one or more proverbial markers [parallelism, rhyme, alliteration, ellipsis, metaphor, etc.], it might "catch on" and be used first in a small family circle, and subsequently in a village, a city, a region, a country, a continent, and eventually the world. The global spread of proverbs is not a pipe dream, since certain ancient proverbs have in fact spread to many parts of the world. Today, with the incredible power of mass media, a newly formulated proverb-like statement might become a bona fide proverb relatively quickly by way of the radio, television, and print media. As with verbal folklore in general, the original statement might well be varied a bit as it gets picked up and becomes ever more an anonymous proverb whose wording, structure, style, and metaphor are such that it is memorable" (Mieder, 2004).

Agreeing with Mieder, I want to add that proverbs may be created on the bases of some traditional events or religious stories as well. Therefore, we can meet some historical and religious names; it might be names of people, saints, 
places, wars and other events in proverbial contents as in Homer sometimes nods, When in Rome, do as the Romans do in English; Bir ko'ngil imorati - ming Makka ziyorati (ww: Making happy one soul is equal to visiting Makkah a thousand times), Gap desa qop-qop, ish desa Samarqanddan top (ww: He can speak sackfully, but, if he has to work, you might find him in Samarkand (he runs away)) in Uzbek.

Having analysed the features of proverbs Norrick clarifies their traditionality, self-containedness, didactic content, fixed form, poetic features, polysemy, connotation, imagery, syntactic features, discourse features and stylistic features (pun, hyperbole, irony, tautology, paradox, etc.) (Norrick, 2014). He argues that proverbs are little texts complete in themselves; their cultural salience provides one's interest in cross-cultural comparison; from the linguistic point of view proverbs unite features of the lexeme, sentence, set phrase, collocation, even text and quote (Norrick, 2014). Because of all these features, proverbs are seen to be a multi-branched issue of both linguistics and folklore.

Moreover, structural features of proverbs (Dundes, 1975; Coinnigh, 2014), the study of proverbs from the folklore point of view (Taylor, 1950), categorization of proverbs (Kuusi, 1972; Permyakov, 1979; Lauhakangas, 2014), semiotic and semantic aspects of proverbs (Cryzbek. 2014), pragmatic and stylistic aspects of proverbs (Jesenšek, 2014), cognitive aspects of proverbs (Lewandowska and Antos, 2014), paremiological minimum (Ďurčo, 2014), proverbs from a corpus linguistic point of view (Steyer, 2014), proverbs in literature (Mieder and Bryan, 1996; Doyle, 2014), proverbs in mass media (Konstantinova, 2008, 2014), proverbs in foreign language teaching (Nuessel, 2003; Fiedler, 2014) and other themes have been learned and still being investigated deeply in the field of paremiology. A great deal of proverbial collections and different types (encyclopaedic, bilingual, etymological, etc.) of proverbial dictionaries have been created for many years in a lot of world languages as well.

\section{Holistic analysis of paremiological graduonymy}

As it was mentioned above, one can find polysemic proverbs in a language. Norrick cites the example of the English proverb A rolling stone gathers no moss having two standard interpretations: 1) a person on the move remains young and 2) a person on the move remains poor (Norrick, 2014). Furthermore, proverbs may show synonymic and antonymic relations, too. For instance:

(1) East or west home is best. $\approx$ There's no place like home.

(2) A man is known by the company he keeps. $\approx$ Birds of feather flock together. Social science and humanities

Generalization of scientific results 
(3) Strike when the iron is hot. $\leftrightarrow$ Slow and steady wins the race.

(4) A friend in court is better than a penny in purse. $\leftrightarrow$ Friends are thieves of time. Synonymic relations are seen in (1) and (2) pairs of proverbs, (3) and (4) are antonymous proverbs accordingly. There are also synonymic and antonymic proverbs in any natural language as well as in the Uzbek language:

(5) Avval o'yla, keyin so'yla. (ww = ee: First think, then speak.) $\approx$ Yetti o'lchab bir kes. (ww: Measure seven times then cut once. ee: Look before you leap.)

(6) Birlashgan o'zar, birlashmagan to'zar. (ww: United group will win, separated group will fail. ee: In unity there is strength.) $\approx$ Birlashgan daryo bo'lar, Tarqalgan irmoq bo'lar. (ww: United group is a river, separated group is a tributary. ee: In unity there is strength.)

(7) Hisoblashgan do'st emas. (ww: A friend does not count what he spends for his friend. ee: Between friends all is common.) $\leftrightarrow$ Hisobli do'st ayrilmas. (ww: No debt makes long friendship. ee: Short debts make long friends.)

(8) O'ychi o'yini o'ylaguncha tavakkalchi ishini bitiradi. (ww: While you are thinking the risk-taker finishes his work. ee: Strike when the iron is hot.) $\leftrightarrow$ Sabrning tagi sariq oltin. (ww: Under patience there is yellow gold. ee: Slow and steady wins the race.)

Since synonymic and antonymic relations occur among proverbs, and graduonymy often involves synonymy and sometimes antonymy in its content there are also graduonymic relations among proverbs. Graduonymic relations of proverbs might be analysed in two ways: holistically and by componential approach.

Holistic approach examines proverbial content as an internally homogenous entity (Grzybek, 2014). Considering a proverb as a complex superstructure according to their sense, their semantic content is essential to be analysed in this approach. Here I aim to test Uzbek proverbs possessing semantic graduonymic relations among them.

In Uzbek linguistics Povali (1975), Berdiyorov and Rasulov (1984), Gasunaeva (1988), Sodikova (1993, 2005), Karomatov and Karomatova (2000), Mirzo (2000), Ibrohim (2002), Mirzayev et al. (2005), Abdusamatov and Hamidkhonova (2006), Madayev (2007) and some other scientists worked on proverbial research and created several paremiographic dictionaries. Such kind of works are being continued nowadays, too.

The Uzbek language is rich in proverbs and they are often poetic. Comparing them with English proverbs one can see that Uzbek proverbs have longer contents which includes frequently two or four lines as a poem. Thematic classifications of English and Uzbek proverbs are also different, some themes of Uzbek proverbs are not found in English proverbial heritage or vice Social science and humanities 
versa because of the difference between English and Uzbek culture and mentality. The proverbs about loving motherland, good and evil, friend and enemy, family, love, hardworking, patience, brave and coward, wise and fool are found in a great number in both languages. For analysing graduonymic relations of proverbs holistically, some Uzbek proverbs on the theme of "wise and fool" will be taken as examples:

(9) Dono o'ylab aytar,

Nodon o'ynab.

ww: The wise thinks while speaking, the fool plays while speaking.

ee: As the fool thinks, so the bell clinks.

(10) Dono aql so'rab horimas,

Nodon nozin qilib bormas.

ww: The wise always asks wit, the fool is too capricious to ask wit.

ee: Folly is wise in her own eyes.

(11) Dono so'ziga bino qo'yar,

Nodon o'ziga.

ww: The wise is proud of his word, the fool is proud of himself.

ee: The fool does think he is wise, but the wise man knows himself to be a fool.

(12) Ahmoq aql o'rgatar.

ww: A fool teaches.

ee: A fool is counted wise when he is silent.

(13) Ahmoq otdan tushsa ham, egardan tushmas.

ww: Although the fool comes down from a horse, he does not come down from the saddle.

ee: Fools will be fools.

Ahmoqqa aytgan bilan gap uqmas,

Xarsangga qoqqan bilan mix o'tmas.

ww: A fool does not listen your sentence, a nail cannot cut stone.

ee: Send a fool to the market, and a fool he will return.

Having considered their semantic sense the Uzbek proverb (9) owns less semantic effectiveness and emotionality than the proverb (10). The proverb (11) is more touchable than (10) respectively. So, from the proverbs (9) to (14) their semantic strength increases gradually. Besides, the proverbs (9), (10), (11) are mainly used in literal sources (poems, stories, novels) while the proverbs (12), (13), (14) often possess oral usage in everyday conversations accordingly. One can find a lot of examples for such kind of graduonymic relations of paremiological semantics in any human language. 
However, the holistic approach of paremiological graduonymy is seen to be very abstract. Because a proverb can manipulate its meaning according to speaker's intention or conversational speech acts in different contexts. It may face to some semantic change in a particular discourse, too. Therefore, considering their all semantic features one cannot declare that graduonymic relations among proverbs are concrete since they show variable semantic peculiarities in real usage of a language by a speaker and a listener.

\section{Componential analysis of paremiological graduonymy}

Having mentioned above, a proverb owns a complex content that is considered to be equal to a sentence because of its complete utterance and grammatical structure in spite of its elliptical features. The sense of proverbs can be understood easily and quickly since they are used repeatedly by the folk in everyday conversation.

The role of its components is essential having an influence on the meaning of proverbs although they express literal, referential, figurative (metaphorical) or contextual meaning in different situations. Investigating graduonymic relations among the components of proverbs may provide results that are more obvious from the semantic point of view. There are plenty of proverbs with graduonym components in both English and Uzbek. For instance, in the English language:

A black hen lays a white egg.

Hope is a good breakfast, but a bad supper.

An hour in the morning is worth two in the evening.

East or west, home is best.

In (15) there are members of the graduonymic row of hen/cock - chick egg that is named "decreasing micrograduonymy". In (16) two graduonymic relations are felt: good - normal - bad (macrograduonymy) and breakfast - dinner - supper (cyclic graduonymy). The proverb (17) also reflects two graduonymic relations: an/one - two - three - four - ... (quantitative graduonymy) and morning - afternoon - evening - night (cyclic graduonymy). The cyclic graduonymy is seen in (18): east - south - west - north (for further information about English proverbs with graduonyms see Abdullaeva, 2017). Comparing types of graduonymic relations with above mentioned Cruse's classification, we can realize that members of some micrograduonymic rows are given as "lexical chains" and some of them as "degree-terms"; much of macrograduonymic lexical units are given as "grade-terms" and some of them as "lexical chains"; cyclic graduonyms are called "lexical helices" and "lexical circles"; and some 
quantitative graduonyms are called "rank-terms" accordingly in his works (Cruse, 1986; Cruse, 2002).

Since the aim of this paper is to analyse paremiological graduonymy in the Uzbek language, I shall study the types of graduonymy that are frequently seen in Uzbek proverbs.

\subsection{Increasing and decreasing micrograduonymy in Uzbek proverbs}

Much seen type of graduonymy is micrograduonymy and it includes increasing and decreasing types according to the direction of its semantic change. Possessing only synonymic relations members of a micrograduonymic row exist in Uzbek paremiological stock, but not in a great number.

\section{Qimirlagan qir oshar,}

Tig'izlagan tog' oshar.

ww: Who is moving he will go over a hillock, who is hurrying he will go over a mountain.

ee: Business before pleasure. / No pain, no gain.

In (19) the increasing graduonymic row of tepalik (mound) - hillock (qir) adir (hill) - tog' (mountain) has its graduonyms, which enliven the proverb.

Birlashgan daryo bo'lar,

Tarqalgan irmoq bo'lar.

ww: United group is a river, separated group is a tributary.

ee: In unity there is strength. / Union is strength.

Here the graduonymyc row of okean (ocean ) - dengiz (sea) - daryo (river) irmoq (tributary) - ko'l (lake) attend in this proverb (20) with its graduonyms. According to the direction of these graduonyms' lexical-semantic relation, this type of graduonymy is decreasing micrograduonymy.

The next proverb also contains members of decreasing graduonymic row, which defines human ages: qari/keksa (old) - o'rta yosh (adult) - yosh (youth) - o'smir (teenager) - bola (child) -- chaqaloq (baby):

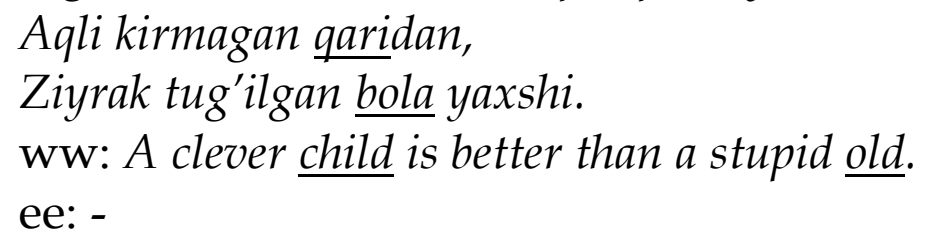

Aqli kirmagan qaridan,

Ziyrak tug'ilgan bola yaxshi.

ww: A clever child is better than a stupid old. ee: -

Some Uzbek proverbs may not have their equivalents in the English language as the proverb (21). Even though the English proverbs Old age doesn't protect from folly and There is no fool like an old fool seem to have similar sense with this proverb, they are not equivalents, because the Uzbek proverb is used to explain the situation of a young person does something well while old one does something worse. 
The following Uzbek proverb and its equivalent in English show obviously that paremiological heritages are the reflections of national customs and traditions (an Uzbek man usually meets with a girl's mother before getting married with that girl):

(22) Onasini ko'rib, qizini ol.

ww: Before getting married with a girl, meet with her mother.

ee: Like father, like son.

The decreasing micrograduonymy of this proverb (22) defines family relationships: buva/buvi (grandparent/grandfather/grandmother) - ota/ona (parent/father/mother) - bola/farzand/o'g'il/qiz (child/son/daughter) - nevara (grandchild/grandson/granddaughter) - evara (great-grandchild/greatgrandson/great-granddaughter). Furthermore, its English equivalent also possesses members of this decreasing graduonymy.

Although a number of Uzbek proverbs own increasing or decreasing micrograduonymy, it is not frequent to find their English equivalents having graduonyms in their contents, moreover, several Uzbek proverbs with micrograduonymic members lack their English equivalents.

\subsection{Macrograduonymy in Uzbek proverbs}

Almost all polar antonyms, and some overlapping and equipollent antonyms constitute graduonymic rows, which are called macrograduonymic rows: long - normal - short, wide - normal - narrow, high - middle - low, heavy normal - light, small - medium - big (polar antonyms); good - normal - bad (overlapping antonyms); boiling - hot - warm - cool - cold - freezing (equipollent antonyms, here boiling and freezing, hot and cold, warm and cool are antonyms).

A macrograduonymic row has two types: unextended and extended. An unextended macrograduonymic row includes three members, which are two antonymous words and one dominant word: small - medium - big, hot - normal - cold and extended macrograduonymic row owns more than three members, which are three or more antonymous words: tiny - small - medium - big enormous - gigantic, boiling - hot - warm - cool - cold - freezing.

Aqllining qadri ahmoqning oldida bilinar.

ww: A wise man's value is felt when you are with a fool.

ee: -

The proverb (23) has the members of this extended macrograduonymic row: telba (asinine, stupid) - nodon (stupid, silly) - ahmoq (absurd, fool) - tentak (fool) - go'sxo'r (crazy) - aqlli (clever, wise) - zehnli (canny, sensible) - oqil (wise) dono (brilliant, wise).

(24) Avval o'yla, keyin so'yla. 


\section{ww=ee: First think, then speak.}

There are members of the unextended macrograduonymic row avval/oldin (first, before, in past) - hozir (now, nowadays) - keyin/so'ngra (then, after, in future) in both Uzbek proverb and its English equivalent.

\subsection{Quantitative graduonymy in Uzbek proverbs}

The phenomenon of graduonymy reflects quantity and quality of notions and things in its sense. Therefore, quantitative graduonymy is the biggest type of graduonymy and one can meet a lot of examples for this kind of graduonyms in proverbial stock of any natural language.

Quantitative graduonyms include all types of numbers (one, two, three, four, five,...; first, second, third, fourth, fifth,...; one-sevenths, two-sevenths, threeseventh, four-seventh, five-seventh,...; etc.), units of measurement (centimetre, meter, kilometre,...; ell, meter, inch...; gram, pound, kilogram, tonne,...; etc.), currencies and units of money (pound (sterling), crown, shilling, pence; etc.), quantitative adverbs (once, twice, thrice; firstly, secondly, thirdly,...; etc.), quantitative nouns (quarter, half, whole; twins, triplets, quadruplets, quintuplets,...; triangle, square, pentagon, hexagon,...; etc.), quantitative adjectives and verbs (single, double, triple, quadruple, quintuple,...; etc.) and other lexical items having quantitative meaning.

Quantitative graduonyms are seen in proverbs that belongs to almost all themes of Uzbek proverbs.

$$
\begin{aligned}
& \text { Bir kalla - kalla, } \\
& \text { Ikki kalla - tilla. } \\
& \text { ww: One head - head, two heads - gold. } \\
& \text { ee: Two heads are better than one. }
\end{aligned}
$$

Although Uzbek and English nations are not genetically related, there are some proverbs having both semantic and structural resemblance in these nations' languages as the proverb (25) and its English equivalent. However, they are not many.

A great amount of Uzbek proverbs contains quantitative graduonyms, and some of them are examined in this work as examples:

Oltmishingda olma eksang,

Yetmishingda yemishin yersan.

ww: If you plant an apple tree when you are sixty years old, you will eat its harvest when you are seventy years old.

ee: -

(27) Bir kalning hiylasi qirq kishini charchatar.

ww: One bald man's slyness will make forty men tired. 
ee: One scabby sheep will mar a whole flock.

$O^{\prime} g^{\prime}$ rining o'zi - bitta, ko'zi yuzta.

ww: A thief-one man, he has hundred eyes.

ee: A thief passes for a gentleman when stealing has made him rich.

Ming yovdan bir dushman yomon.

ww: One enemy is worse than thousand foes.

ee: Of two evils choose the least.

Ayol so'm qilar, erkak - chaqa.

ww: A woman makes soums (Uzbek currency), a man makes copper coins

or A woman makes pounds, a man makes pennies.

ee: -

The sense of the proverb (30) is directly connected with the Uzbek family tradition: a man works and earns money while his wife keeps and spends it for his family household without wastefulness; therefore, this proverb says a man cannot save money as a woman does.

\section{Yaxshi otga bir qamchi,}

Yomon otga ming qamchi.

ww: A good horse deserves one beat, a bad horse deserves thousand beats. ee: A good dog deserves a good bone.

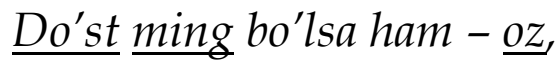

Dushman bir bo'lsa ham - ko'p.

ww: Even you have thousand friends, it is few, Even you have one enemy, it is many.

ee: There is no little enemy.

The proverbs (31) and (32) keeps two types of graduonymy in their contents: macrograduonymy (yaxshi (good) - o'rtacha (normal, average) - yomon (bad); do'st (friend) - tanish/birodar (familiar person) - dushman (enemy); ko'p (many/much) - yetarli (enough, normal) - kam (few/little)) and quantitative graduonymy (bir (one) -...-ming (thousand)).

\subsection{Cyclic graduonymy in Uzbek proverbs}

As Djumabaeva cites in cyclic graduonymy graduonyms' direction is round and cyclic, they possess one beginning or ending point for a certain event or notion, but members of a cyclic graduonymic row cannot be antonymous to each other (Djumabaeva, 2014). They are usually adverbs and nouns defining time (Sunday - Monday - Tuesday - Wednesday - Thursday Friday - Saturday; spring - summer - autumn/fall - winter; morning - afternoon evening - night; east - south - west - north; day - week - month - year - century; yesterday - today - tomorrow; etc.) and adjectives naming colours (brown - orange Social science and humanities

Generalization of scientific results 
- red-yellow - green - blue - purple - pink - ...). They are also frequently found in Uzbek proverbs:

Dangasaning ishi bitmas,

Yoz kelsa ham qishi bitmas.

ww: A lazy man's work never ends, though summer comes, his winter does not end (he considers it is winter and it is not time to work even it is summer)

$$
\text { ee: A lazy sheep thinks its wool heavy. }
$$

Yoz bo'yi yotar,

Qish bo'yi qotar.

ww: He lies during summer, freezes during winter.

ee: Idleness rusts the mind.

Bugun yupun, ertaga butun.

ww: Today shabby, tomorrow well-dressed.

ee: Feast today, fast tomorrow.

The Uzbek proverb (35) means that if you keep what you have today, you get more things tomorrow. Its English equivalent says if you spend all what you have today, you get nothing tomorrow. However, they have same theme and meaning, besides, same graduonyms.

Bugungi ishni ertaga qo'yma.

ww=ee: Never put off till tomorrow what you can do today.

The proverb (36) and its English equivalent are same both structurally and semantically.

The following Uzbek proverbs' equivalents do not exist in the English language:

Lumadan umiding bo'lsa, Payshanbadan harakat qil.

ww: If you expect something from Friday, begin your attempt on

Thursday.

ee: -

(38) Palov desang, payshanbaga, Do'lma desang, dushanbaga.

ww: Eat pilaf on Thursday, eat dolma on Monday.

ee: -

Containing culturemes pilaf (palov - famous Uzbek national dish) and dolma (do'lma - Uzbek national dish), the proverb (38) reflects the Uzbek tradition that the Uzbek eat pilaf usually on Thursday and dolma on Monday.

(39) Kuzning bir kuni qishning bir oyini boqar.

ww: One day of autumn feeds one month of winter.

ee: - 
The proverb (39) means that if you harvest one day in autumn then you eat it during one month in winter. Besides, this proverb carries the members of two cyclic graduonymic rows: autumn - winter - spring - summer and day - week - month - year - century.

Considerable number of cyclic graduonymy exist in Uzbek proverbial stock and they give semantic colour to the proverbs as well.

\subsection{Unique graduonymic rows in Uzbek proverbs}

Unique graduonymy is a semantic paradigm that equivalents of its graduonyms of one language do not exist fully in other languages. Djumabaeva conveys this type of graduonymy and gives examples for unique graduonymy from the English language: baby - twins - triplets - quadruplets quintuplets - sexduplets (only baby and twins have Uzbek equivalents: baby chaqaloq and twins - egizaklar, other graduonyms of this row are translated into Uzbek with giving explanations including two or more words, which cannot be graduonyms) (Djumabaeva, 2014).

The Uzbek language also possesses unique graduonymic rows, particularly, unique graduonyms are also seen in the contents of Uzbek proverbs that most of them do not have English equivalents as following ones:

Kaltak o'qtalganga cho'qmor ko'tar.

ww: If someone hits you with a stick, hit him with a big stick.

Unique graduonymic row: kaltak (stick) - cho'qmor (big special stick used for hitting in wars) - to'qmoq (cudgel, bigger than chokmor) - shashpar (wooden cudgel with iron tip used for hitting in wars, bigger than cudgel) - gurzi (wooden or metal arm with wide round tip usually with sharp arrow-head, bigger than shashpar). These lexemes reflect Uzbek war arms as culturemes. The proverb (40) states that if someone does bad things to you, punish him as for he should understand his guilt.

$$
\text { Alp-enadan, tulpor - biyadan. }
$$

ww: A woman gives a birth to a strong man, a mother horse gives a birth

to a fast horse.

Unique graduonymic row: qulun (1 year old colt) - toy/toychoq (2 years old colt) - do'non (3 years old colt) - ayg'ir (young male horse)/baytal (filly) biya (mother horse)/tulpor (fast horse). The most Uzbek men use horses in everyday life; they like and keep this domestic animal in their yards or farms. That is why they use different words to name different ages and sex of a horse. The proverb (41) says that no one comes from the sky, women give birth and grow anyone whether he is strong or weak, therefore we should respect and take care our mothers. 


$$
\begin{aligned}
& \text { Osh - avliyo, non-payg'ambar. } \\
& \text { ww: Pilaf-saint, bread - prophet. }
\end{aligned}
$$

Unique graduonymic row: mulla (mullah, Islamic religious teacher) imom (imam, Islamic religious leader) - avliyo (Islamic religious saint) payg'ambar (Islamic religious prophet). Because of the religion of the Uzbek nation several Uzbek proverbs contains Islamic religious words and phrases as the proverb (42). The proverb is about valuing food like valuing saints and prophets, and not wasting it. In Uzbek culture bread is the dearest food and pilaf is the most favourite dish.

Qirq igna bir juvoldiz bo'lmas.

ww: Forty needles cannot be one juvoldiz.

Unique graduonymic row: igna (needle) - juvoldiz (thick bent needle used for sewing a sack) - bigiz (large needle with a thick handle and a sharp-pointed hook and used for sewing shoes). Using the types of needles metaphorically in the Uzbek proverb (43), it mentions that some people and things are not substitutable. For instance, no one can substitute parents' love or nothing can substitute the sun, etc. Furthermore, this proverb also owns quantitative graduonyms (forty and one) in its content.

This type of graduonymy is found but not frequently in the paremiological stock of the Uzbek language. One should be familiar with Uzbek lifestyle, traditions and culture to understand the sense of proverbs with unique graduonyms.

\section{Conclusion}

Summing up this paper, graduonymy as a universal phenomenon of general linguistics has a considerable role in semantics, especially, in the semantics of paremiology. Having investigated paremiological graduonymy in the Uzbek language with holistic and componential analyses, I note that studying graduonymic relations of proverbs provides valuable results about the semantics of paremiology.

Moreover, componential analysis gives more concrete solutions for disclosing the issue of paremiological graduonymy than the holistic one. In this research I have analysed 644 Uzbek proverbs having graduonyms in their contents: 275 (43\%) of them contain quantitative graduonyms, $127(20 \%)$ of them contain micrograduonyms, $80(12 \%)$ of them have cyclic graduonyms, 74 $(11 \%)$ of them have macrograduonyms, $56(9 \%)$ of them have unique graduonyms, and $32(5 \%)$ of them contain two or more different types of graduonyms in a proverb content. Considering these results, I conclude, Uzbek proverbial stock reflects all types of graduonymy in its content; moreover, the Social science and humanities

Generalization of scientific results 
most frequent type of graduonymy in the contents of proverbs is quantitative graduonymy, and the least frequent type is unique graduonymy accordingly. Although all proverbs of a language express the nation's culture that owns the language, proverbs having unique graduonyms show the nation's lifestyle, traditions and culture more obviously.

There are not always English equivalents for Uzbek proverbs; so, some of Uzbek proverbs having graduonyms in their contents do not have their equivalents in English, too. Even if their English equivalents exist, few of those equivalents keep graduonyms in their contents. However, graduonyms in proverbial structures enliven the meaning and emotionality of proverbs and make them touchable, effective, poetic and colourful from the semantic point of view. 


\section{References:}

Abdullaeva, N.E. (2017): English Proverbs with Graduonyms. European Research: Innovation in Science, Education and Technology, 10(33): 51-53.

Allan, K. (2006): Natural Language Semantics. Oxford: Blackwell Publishers, pp. 1-3.

Arifjonova, Sh.G. (1996): Lexical Graduonymy in the Uzbek Language (O'zbek tilida lug'aviy graduonimiya). Bukhara: Bukhara, pp. 30-38.

Begmatov, E., Nematov, H., Rasulov, R. (1989): Lexical Microsystem and its Research Methods (Leksik mikrosistema va uning tadqiq metodikasi). O'zbek tili va adabiyoti, 6: 35-40.

Berdiyorov, H., Rasulov, R. (1984): Paremiological Dictionary of the Uzbek Language ( $\mathrm{O}^{\prime}$ zbek tilining paremiologik lug'ati). Tashkent: O'qituvchi.

Bierwisch, M. (1989): The Semantics of Gradation. In: Bierwisch, Lang E (eds) Dimensional Adjectives: Grammatical Structure and Conceptual Interpretation. Berlin: Springer, pp. 72-75.

Bozorov, O. (1995): Graduonymy in the Uzbek language (O'zbek tilida darajalanish). Tashkent: Fan, pp. 34-35.

Coinnigh, M.M. (2014): Structural Aspects of Proverbs. In: Gotthardt HH, Varga MA (eds) Introduction to Paremiology: A Comprehensive Guide to Proverb Studies. Warsaw/Berlin: De Gruyter Open, pp. 113-132.

Cruse, D.A. (1986): Lexical Semantics. Cambridge: Cambridge University Press, pp. 183-200.

Djumabaeva, J. (2014): Lexical Graduonymy in the Uzbek and English languages ( $\mathrm{O}^{\prime}$ zbek va ingliz tillarida leksik graduonimiya). Tashkent: Mumtoz so'z, pp. 6-30.

Djumabaeva, J. (2016a): Lexical and Stylistic Graduonymy in the Uzbek and English languages ( $\mathrm{O}^{\prime}$ zbek va ingliz tillarida leksik hamda stilistik graduonimiya). Tashkent: Mumtoz so'z, pp. 10-24.

Djumabaeva, J. (2016b): Graduonymy as a Semantic Phenomenon in Uzbek Linguistics. Arts and Social Sciences Journal, 7: 208. doi:10.4172/21516200.1000208 .

Doyle, Ch.C. (2014): Proverbs in Literature. In: Gotthardt HH, Varga MA (eds) Introduction to Paremiology: A Comprehensive Guide to Proverb Studies. Warsaw / Berlin: De Gruyter Open, pp. 262-273.

Dundes, A. (1975): On the Structure of the Proverb. Proverbium, 25: 961973.

Ďurčo, P. (2014): Empirical Research and Paremiological Minimum. In: Gotthardt HH, Varga MA (eds) Introduction to Paremiology: A 
Comprehensive Guide to Proverb Studies. Warsaw/Berlin: De Gruyter Open, pp. 183-201.

Fielder, S. (2014): Proverbs and Foreign Language Teaching. In: Gotthardt HH, Varga MA (eds) Introduction to Paremiology: A Comprehensive Guide to Proverb Studies. Warsaw/Berlin: De Gruyter Open, pp. 294-311.

Galperin, I.R. (1971): Stylistics. Moscow: Visshaya shkola, p. 220-221.

Giyasov, S. (1986): Semic Analysis of Subjective Marking Adjectives in the Uzbek Language ( $\mathrm{O}^{\prime}$ zbek tilida subyektiv baho sifatlarining semik tahlili). O'zbek tili va adabiyoti, 2: 28-32.

Grzybek, P. (2014): Semiotic and Semantic aspects of the Proverb. In: Gotthardt HH, Varga MA (eds) Introduction to Paremiology: A Comprehensive Guide to Proverb Studies. Warsaw/Berlin: De Gruyter Open, pp. 69-81.

Jacobson, R., Fant G.M., Khalle, M. (1962): Introduction to the Analysis of Speech (Введение в анализ речи). Новое в лингвистике, 2: 173-186.

Jesenšek, V. (2014): Pragmatic and Stylistic Aspects of Proverbs. In: Gotthardt HH, Varga MA (eds) Introduction to Paremiology: A Comprehensive Guide to Proverb Studies. Warsaw/Berlin: De Gruyter Open, pp. 133-158.

Karomatova, K.M., Karomatov H.S. (2000): Proverbs, Maqollar, Пословицы. Tashkent: Mehnat.

Katsnelson, S.D. (1965): The Contents of Words, meaning and sense (Содержание слова, значение и обозначение). Мoscow: Наука, pp. 81-83.

Kennedy, C., McNally, L. (2005): Scale Structure, Degree Modification and the Semantics of Gradable Predicates. Language, 81(2): 345-381.

Konstantinova, A. (2014): Proverbs in Mass Media. In: Gotthardt HH, Varga MA (eds) Introduction to Paremiology: A Comprehensive Guide to Proverb Studies. Warsaw/Berlin: De Gruyter Open, pp. 276-290.

Lauhakangas, O. (2014): Categorization of Proverbs. In: Gotthardt HH, Varga MA (eds) Introduction to Paremiology: A Comprehensive Guide to Proverb Studies. Warsaw/Berlin: De Gruyter Open, pp. 49-66.

Lewandowska, A., Antos, G. (2014): Cognitive Aspect of Proverbs. In: Gotthardt HH, Varga MA (eds) Introduction to Paremiology: A Comprehensive Guide to Proverb Studies. Warsaw/Berlin: De Gruyter Open, pp. 162-181.

Mieder, W. (2004): Proverbs: A handbook. Westport, Connecticut: Greenwood Press, p. 9 
Mieder, W. (2014): Origin of Proverbs. In: Gotthardt HH, Varga MA (eds) Introduction to Paremiology: A Comprehensive Guide to Proverb Studies. Warsaw/Berlin: De Gruyter Open, pp. 28-44.

Mirzo, Sh. (2000): English - Uzbek Proverbs and Aphorisms (Inglizcha o'zbekcha maqol va matallar). Tashkent: Gafur Gulom, pp. 4-35.

Morris, C.W. (1938): Foundations of the Theory of Signs. Chicago: The University of Chicago Press, p. 6.

Norrick, N.R. (2014): Subject Area, Terminology, Proverb Definitions, Proverb Features. In: Gotthardt $\mathrm{HH}$, Varga MA (eds) Introduction to Paremiology: A Comprehensive Guide to Proverb Studies. Warsaw/Berlin: De Gruyter Open, pp. 7-27.

Saussure, F. (1916): Course in General Linguistics (Cours de linguistique generale). Geneva: Open Court Classics.

Speake, J. (2008): The Oxford Dictionary of Proverbs (fifth edition). New York: Oxford University Press Inc.

Stepanov, Y.S. (1975): The Bases of General Linguistics (Основы общего языкознания). Moscow: Просвещение, p. 38.

Steyer, K. (2014): Proverbs from a Corpus Linguistic Point of View. In: Gotthardt HH, Varga MA (eds) Introduction to Paremiology: A Comprehensive Guide to Proverb Studies. Warsaw/Berlin: De Gruyter Open, pp. 206-227.

Taylor, A. (1950): Proverb. In: Leach M (eds) Standard dictionary of folklore, mythology and legend. New York: Funk \& Wagnall, pp. 902-905.

Trubetskoy, N.S. (1960): Bases of Phonology (Основы фонологии). Moscow: Иностранная литература, p. 83.

Vokhidova, N. (2008): Überlegungen zur Erweiterung lexicalischsemantischer Ressourcen durch die Graduonymie. Workshop zur Konvens "Lexical-Semantic and Ontological Resources Maintenance, Representation and Standards", 119-128.

Yespersen, O. (1958): The Philosophy of Grammar (Философия грамматики). Moscow: Изд-во иностранной литературы, p. 375.

https://en.wikipedia.org/wiki/Paremiology\#cite_note-1 